\title{
Culturally Based Practice in Neonatal Procedural Pain Management: A Mini Review
}

\author{
Siti Yuyun Rahayu Fitri ${ }^{1 *}$, Viera Wardhani ${ }^{2}$, Windy Rakhmawati ${ }^{1}$, Tuti Pahria ${ }^{3}$ and \\ Sri Hendrawati ${ }^{1}$ \\ 1 Pediatric nursing department, Faculty of Nursing, Universitas Padjadjaran, Bandung, Indonesia, ${ }^{2}$ Faculty of Medicine, \\ Universitas Brawijaya, Malang, Indonesia, ${ }^{3}$ Medical Surgical Nursing Department, Faculty of Nursing, Universitas \\ Padjadjaran, Bandung, Indonesia
}

\section{OPEN ACCESS}

Edited by:

Carlo Bellieni,

University of Siena, Italy

Reviewed by:

Hercilia Guimarães,

University of Porto, Portugal

Asir John Samuel,

Maharishi Markandeshwar

University, India

${ }^{*}$ Correspondence:

Siti Yuyun Rahayu Fitri

siti.yuyun@unpad.ac.id

Specialty section:

This article was submitted to

Neonatology,

a section of the journal

Frontiers in Pediatrics

Received: 23 April 2020

Accepted: 27 July 2020

Published: 03 September 2020

Citation:

Fitri SYR, Wardhani V, Rakhmawati W,

Pahria T and Hendrawati S (2020)

Culturally Based Practice in Neonatal

Procedural Pain Management: A Mini

Review. Front. Pediatr. 8:540

doi: 10.3389/fped.2020.00540
Cultural factors have gradually become important considerations in health services, including in pain management for adult and pediatric patients. However, research on culturally based pain management in neonates remains limited. This mini review aims to provide an overview of procedural pain management in neonates based on cultural approaches from various countries. The review found that there are several analyses of pain management procedures for neonates developed from cultural practices, namely, acupuncture, foot massage and reflexology, Yakson touch therapy, and aromatherapy. The acupuncture method (invasive and non-invasive) is more widely studied using randomized controlled trials (RCTs) than the other methods because the techniques applied can be standardized and measured. There are indications of the positive impact of all the methods examined in this review, but the results of studies have not been consistent because of the diversity of outcome measurement methods used and because of the difficulty of creating standardized procedures to measure pain management methods that are based on cultural practices.

Keywords: acupuncture, aromatherapy, culture, foot massage, neonates, pain management, procedural pain

\section{INTRODUCTION}

Neonates in neonatal intensive care units (NICUs) experience painful procedures, with a range between 7.5 and 17.3 per neonate per day (1); the most common procedures being heel lancing, suctioning, tape removal, nasogastric/orogastric tube insertion, intravenous line insertion, venipuncture, and peripherally inserted central catheter line insertion (2).

Prevention and treatment of pain in neonates are highly important given the impact of shortterm and long-term pain on various aspects of neonatal well-being and development. Despite the many treatments that cause pain in neonates, pain management for these patients conducted by health workers remains limited (3-5). Previous studies have referred to various types of procedural pain management methods in neonates (6-11). Generally non-pharmacological treatments for pain relief in neonates can be categorized into three types of approaches: environmental control, feeding methods, and other interventions (6). We summarize the current evidence for non-pharmacological culturally based treatment for pain relief in neonates (Table 1).

Currently, cultural approaches are being increasingly applied in healthcare for neonates, including in procedural pain management. Medical professionals need to consider cultural practices that are trusted by the public when providing health services, so that such practices 
TABLE 1 | Non-pharmacological analgesia for procedural pain in neonates.

\begin{tabular}{ll}
\hline Approach & Type of analgesia \\
\hline Environmental control & Skin to skin contact \\
& Kangaroo mother care \\
& Swaddling \\
& Facilitated tucking \\
& Therapeutic touch/massage \\
& Musical therapy \\
& Auditory recognition \\
& Olfactory/aromatherapy recognition \\
& Breast milk \\
Feeding methods & Breastfeeding \\
& Nonnutritive sucking \\
& Acupuncture \\
Sucrose/glucose solution \\
Sensorial saturation/multisensory stimulation
\end{tabular}

become more widely accepted in the community (12). In addition, culture has been found to be one of the main elements in nursing (known as cultural nursing) that makes nursing services safer and more humane (13).

Culture is a framework that guides human behavior in many situations. This means that culture can direct people in finding ways to overcome the health problems they face, including pain management. Cultural factors have driven the development of a variety of pain management methods in different community groups (14). Various studies have noted that culture influences the meaning of, and responses to, individual pain, including in children. However, most studies of cultural practices in pain management in children do not consider neonates. Sujatha (15) stated that there is a strong relationship between cultural practices in the community and neonatal care. The purpose of this mini review is to summarize the findings of studies on procedural pain management methods for neonates that are based on culture, tradition, and ethnicity. The results of the review are expected to provide an overview of the application of culturally based pain management to neonates and encourage further study to ensure that pain management procedures in neonates are safe and tested according to each culture.

\section{METHOD}

A mini review was conducted to explore information on traditional or culturally based neonatal pain management in various ethnic communities. The literature search used neonatal procedural pain management as the research topic. The keywords and phrases included were a combination of "neonatal" and the search terms "culture," "traditional," "ethnicity," "procedural pain," "pain management," "acupuncture," "Yakson," "massage," "aromatherapy." These were further enhanced using the terms "and" and "or." The search for literature was conducted using the Scopus, Science Direct, and PubMed databases from 2000 to 2020, and restricted to English-language articles. The studies included in the review were not limited to any specific research designs.

\section{RESULTS}

\section{Acupuncture}

Acupuncture is a form of culturally based pain management that has been widely studied. Acupuncture is a method of traditional Chinese medicine that has its own system for the diagnosis and treatment of disease. Scientific research into the mechanisms of acupuncture began in $\sim 1950$ when a research group at Peking University published an important pharmacological study (16). Since the 1970s, the mechanism of acupuncture analgesia has been widely explored (17). Acupuncture is based on the idea of energy ("Chi") circulating through the body by using meridians as pathways (18). Acupuncture has begun to be applied in children, although the research on the efficacy of this method remains limited. Reviews have reported that the limitations of acupuncture application in children are caused by children's fear of needles, infants' or toddlers' lack of cooperation, risk of infection, and the lack of clarify about the safety of acupuncture given that responses to therapy are difficult to evaluate during in infancy (19).

There are two different strategies for performing acupuncture therapy: manual and electro acupuncture (17). Electro acupuncture is a modified form of manual acupuncture. Manual acupuncture or traditional acupuncture is an invasive method that involves insertion and manipulation of fine needles in specific cutaneous areas that are associated with high electrical activity and peripheral nerve connections. Recently, electro acupuncture has also begun to be used. This procedure involves using modifications of needles in acupuncture to make the procedure non-invasive, for example, magnets, electrical current without needles, lasers, pressure (acupressure), and heat (moxibustion) (20).

The use of invasive and non-invasive methods of acupuncture in neonates to reduce procedural pain has been examined only in several studies. In a study using invasive acupuncture to reduce pain in 10 neonates who had undergone the heel prick procedure, acupuncture was performed by competent doctors by inserting thin, sterile disposable needles $(0.22 \times 1.5 \mathrm{~mm})$ at the Yintang acupuncture point (EXHN3). This acupuncture point is located midway between the medial ends of the eyebrows. Each needle was kept in place for $30 \mathrm{~min}$ and then removed (21). Pain was assessed using the Neonatal Infant Pain Scale (NIPS). The results showed that acupuncture using this method significantly reduced pain scores. Other than this study, no other study on invasive acupuncture using needle is available so far.

Non-invasive acupuncture has also been used in neonates undergoing hospital treatment (Table 2). This mini review identified seven research articles that examined non-invasive acupuncture in neonates (six articles on pain management caused by heel prick and one article that did not examine any specific procedure). Review of the studies found variations in the techniques and the acupuncture points used. Four noninvasive acupuncture methods were examined in the studies: 
TABLE 2 | Application of noninvasive acupuncture in neonates.

\begin{tabular}{|c|c|c|c|c|c|c|c|}
\hline References & Procedure & $\begin{array}{l}\text { Electro } \\
\text { Acupuncture }\end{array}$ & Acupuncture Point & Patients (n) & Outcomes & Findings & Design \\
\hline $\begin{array}{l}\text { Abbasoglu et al. } \\
\text { (22) }\end{array}$ & Heel prick & Acupressure & $\begin{array}{l}\text { BL60 (in a depression } \\
\text { between the tip of the } \\
\text { lateral malleolus and } \\
\text { the Achilles tendon) } \\
\text { K3 (medial aspect of } \\
\text { the foot, posterior to } \\
\text { the medial malleolus } \\
\text { and in the depression } \\
\text { between the tip ofthe } \\
\text { medial malleolus and } \\
\text { the Achilles tendon) }\end{array}$ & 32 & $\begin{array}{l}\text { PIPP score } \\
\text { Duration of } \\
\text { procedure } \\
\text { Duration } \\
\text { of crying }\end{array}$ & $\begin{array}{l}\text { No significant finding in } \\
\text { PIPP score } \\
\text { Significant reduction in } \\
\text { mean duration of } \\
\text { procedure } \\
\text { Significant finding in } \\
\text { mean duration of crying }\end{array}$ & $\begin{array}{l}\text { Prospective } \\
\text { RCT }\end{array}$ \\
\hline $\begin{array}{l}\text { Abbasoglu et al. } \\
\text { (23) }\end{array}$ & Heel prick & $\begin{array}{l}\text { Laser } \\
\text { acupuncture (LA) }\end{array}$ & $\begin{array}{l}\text { Yintang (On the } \\
\text { forehead, at the } \\
\text { midpoint between the } \\
\text { two medial ends of the } \\
\text { eyebrow) }\end{array}$ & 42 & $\begin{array}{l}\text { NIPS } \\
\text { Duration of } \\
\text { procedure } \\
\text { Duration } \\
\text { of crying }\end{array}$ & $\begin{array}{l}\text { No significant finding in } \\
\text { NIPS score } \\
\text { Significant reduction in } \\
\text { mean duration of } \\
\text { procedure } \\
\text { Mean time in duration of } \\
\text { crying was longer in LA }\end{array}$ & $\begin{array}{l}\text { Prospective } \\
\text { Unblind } \\
\text { Uncontrol }\end{array}$ \\
\hline $\begin{array}{l}\text { Mitchell et al. } \\
\text { (24) }\end{array}$ & Heel prick & $\begin{array}{l}\text { Electrical } \\
\text { stimulation }\end{array}$ & $\begin{array}{l}\text { ST36 (one finger width } \\
\text { lateral from the } \\
\text { anterior crest of the } \\
\text { tibia, in the tibialis } \\
\text { anterior muscle) } \\
\text { SP6 (above the tip of } \\
\text { the medial malleolus } \\
\text { on the posterior } \\
\text { border of the tibia) } \\
\text { BL60 } \\
\text { KI3 (lower leg) }\end{array}$ & 162 & $\begin{array}{l}\text { PIPP score } \\
\text { HRV } \\
\text { Salivary cortisol }\end{array}$ & $\begin{array}{l}\text { No significant finding for } \\
\text { PIPP score } \\
\text { No significant finding for } \\
\text { HRV } \\
\text { No significant finding for } \\
\text { salivary cortisol }\end{array}$ & $\begin{array}{l}2 \times 2 \text { factorial RCT } \\
\text { Double blind }\end{array}$ \\
\hline Yates et al. (25) & Heel prick & $\begin{array}{l}\text { Electrical } \\
\text { stimulation } \\
(1.0 \mathrm{~mA}, 2 \mathrm{~Hz})\end{array}$ & ST36, SP6, KI3, BL60 & 30 & $\begin{array}{l}\text { Skin assessment } \\
\text { Vital signs } \\
\text { PIPP score }\end{array}$ & $\begin{array}{l}\text { No adverse effects } \\
\text { No significant change in } \\
\text { vital signs No significant } \\
\text { change in PIPP score }\end{array}$ & $\begin{array}{l}\text { Prospective } \\
\text { Unblind } \\
\text { Uncontrolled } \\
\text { Open label trial }\end{array}$ \\
\hline Tugcu et al. (27) & - & Acupressure & Yintang (EX-HN3) & 17 & $\begin{array}{l}\text { Neonatal skin } \\
\text { perfusion } \\
\mathrm{SaO}_{2} \\
\text { Pulse rate }\end{array}$ & $\begin{array}{l}\text { Increases in peripheral } \\
\text { perfusion } \\
\text { Increases in } \mathrm{SaO}_{2} \text {, values } \\
\text { Significant decrease in } \\
\text { pulse rate }\end{array}$ & $\begin{array}{l}\text { Prospective } \\
\text { Unblind } \\
\text { Uncontrolled }\end{array}$ \\
\hline Chen et al. (28) & Heel prick & $\begin{array}{l}\text { Magnetic } \\
\text { acupuncture }\end{array}$ & $\begin{array}{l}\text { Five auricular points } \\
\text { (cingulate gyrus, } \\
\text { thalamus, omega, } \\
\text { point zero, and } \\
\text { shenmen) }\end{array}$ & 40 & PIPP score & $\begin{array}{l}\text { Significant decrease in } \\
\text { PIPP score }\end{array}$ & $\mathrm{RCT}$ \\
\hline
\end{tabular}

HRV, heart rate variability; PIPP, premature infant pain profile; NIPS, Neonatal Infant Pain Scale; LA, laser acupuncture; HR, heart rate; SaO $\mathrm{O}_{2}$ oxygen saturation; RCT, randomized controlled trial.

acupressure, laser acupuncture, magnetic electro puncture, and electrical stimulation. Nine acupuncture points used are in the body area and five are in the auricular area. The subjective measurement tools were the NIPS and crying duration, and the objective measurement tools used were the premature infant pain profile (PIPP), heart rate variability (HRV), and saliva testing. While some of the studies reviewed found that acupuncture decreases pain scores in the objective measures, the results were not consistent across the studies.

It remains unclear whether invasive or non-invasive acupuncture methods are more effective as analgesic interventions for pain caused by procedural treatments in neonates (19). This lack of clarity is partly because the efficacy of acupuncture depends significantly on the ability of the clinician 
and on the compliance of the clinician in applying principles of safety and hygiene $(19,29)$. However, non-invasive techniques may be more suitable for neonates given that there is no clear evidence of the short-term or long-term effects of acupuncture (20). Moreover, the skin of premature babies and newborns is very thin and shows physiologic and histologic peculiarities. This means it is important for to ensure the skin remains undamaged and that no potential entry point for infectious diseases is created (30). Thus, non-invasive interventions should be considered for premature babies and newborns $(25,31,32)$. However, there are no data or research studies that prove which non-invasive methods of acupuncture are superior or which acupuncture points are safe and appropriate for neonates.

Acupuncture has the potential to decrease neonatal exposure to potentially neurotoxic analgesics and sedative agents (19). The limited data available suggest that acupuncture is a safe nonpharmacologic treatment option for pain reduction in term and preterm infants. Chen et al. (20) noted that currently, there is a need for a high-quality well-designed and standardized RCT that uses physiological outcomes to evaluate the efficacy of acupuncture. A 2016 review of acupuncture (33) concluded that studies that showed a lack of efficacy or uncertain results outweighed studies with positive results. The possible reasons for this were related to the overall quality of research, use of poorly designed sham acupuncture, lack of standard procedures for locating points and needling, and lack of attention to individual differences. Acupuncture may have a positive pain-relieving effect in neonates. However, given the low number of available high-quality trials and the lack of heterogeneity across studies, it is not possible to state clear recommendations $(33,34)$.

\section{Foot Massage and Reflexology}

The most ancient references to the use of massage came from China ( 2700 BC). Massage therapy can be applied to adults and children (35). Given the worldwide popularity of massage therapy, there are many common types of massage therapy available, including Swedish massage, Shiatsu, Rolfing, reflexology, myofascial release, and craniosacral therapy (36). In India, Bangladesh, Nepal, and other neighboring countries, neonatal massage has been a traditional practice (37). Massaging the feet and hands stimulates the mechanoreceptors that activate the "nonpainful" nerve fibers that prevent pain transmission from reaching consciousness (38).

Foot massage has been shown to improve physiological and behavioral stability and to lower the severity of pain responses to heel lancing in preterm infants, as well as to decrease the heel lancing duration (39). In addition, foot massage has been found to reduce pain responses to procedures other than heel stick in NICUs (40). Foot massage is considered to be as effective as acupressure in reducing pain in neonates undergoing heel stick (26).

Foot massage is often identified with foot reflexology $(40,41)$. However, there is a slight difference because foot reflexology is not simply foot massage (42), with the principal difference being the intensity level of the massage. A foot massage does not usually affect the deeper tissue, nor it is centered on specific pressure points. In contrast, reflexology is the study of how one part of the human body (in this case, the feet and hands) relates to other parts of the body (43) and considers that the hands and feet contain reflex zones. In addition, Foot reflexology reduces the pain in vaccinating infant aged $0-12$ months (44).

Neonatal foot massage and reflexology were considered together in this review because reflexology has received very little research attention particularly in relation to procedural pain relief in neonates. The absence of standardized studies of reflexology, the inadequate use of study protocols and guidelines, and the data heterogeneity mean that the results of studies on reflexology cannot be generalized and there can be no conclusion about whether this type of massage has a positive effect on neonates in relation to procedural pain management (43). To provide any evidence for the efficacy of this method, wellstructured double-blind RCTs are required.

\section{Yakson Touch}

In Korea, Yakson culture has been explored for use as a nonpharmacological analgesic in neonates (45-50). The compound word "Yakson" comes from yak, which means medicine, and son, which means hands, thus the literal meaning of Yakson is "medicine hands" (51). Yakson touch is a traditional touching method where mothers and grandmothers caress and massage their sick children's area of pain using supernatural power (46). Yakson touch employs a pure and natural action where a mother or a grandmother puts her hand on the pain area of the child and caresses or massages the area to relieve the child's pain or discomfort. The attributes of Yakson touch are earnest wish, soothing, physical expression, mutual interaction, and family ties (51).

Several studies have examined Yakson touch as a nonpharmacologic analgesic method in neonates. Some studies apply Yakson touch to provide a calming effect on neonates and infants. Although Yakson touch is not specifically applied to reduce pain, the effect of inducing tranquility is also the basis of several non-pharmacological analgesic methods. Therefore, this review discusses Yakson touch as a method of pain relief for neonates.

Yakson touch was performed on neonates during heel stick procedures to reduce pain by maintaining oxygen saturation during the procedure, with findings of a significant effect on pain reduction (46). In the study, Yakson touch was conducted by nurses. The study also noted that Yakson touch can be performed alone or in combination with other pacifiers during the heel stick procedure.

Compared with other touch therapies, Yakson touch shows a more rapid calming effect because it stimulates a sense of comfort during the process. However, in gentle human touch (GHT) therapy, the calming effect appears only after the therapy process is completed (47). In the study, that babies who received Yakson intervention had longer sleep times. Other studies also found that Yakson touch led to high sleep scores compared with the control group (48) and the GHT group (49). As is widely acknowledged, prolonged sleep is essential for optimum healing (52). Thus, there is some evidence for the efficacy of Yakson touch as a non-pharmacological intervention for managing procedural pain in neonates. 


\section{Aromatherapy}

Aromatherapy refers to the inhalation and topical application of authentic essential oils from aromatic plants to restore or enhance health, beauty, and well-being (53). It is well known that aromatic oils were used in China, in Australia by Indigenous Australians, in India, and in ancient Egypt (53). Currently, the use of aromatherapy has been applied in healthcare, including in pediatric patients. In the field of neonatology, aromatherapy has begun to be applied to manage procedural pain. Some of the aromas used are lavender, vanilla, and breastmilk.

The aroma of breastmilk was found to have an analgesic effect on premature babies and can be used as a safe method of pain reduction (54). The aroma of breastmilk can also improve pulse and oxygen saturation when neonates undergo venipuncture procedures (55), and is used to calm premature babies during and after venipuncture (56). Another study found that breastmilk aroma had a more significant effect on changes in heart rate and oxygen saturation in neonates during and after venipuncture than the aroma of vanilla (57). It was also found to decrease heart rate variability and oxygen saturation of premature babies. In contrast, vanilla aroma was not found to create any significant changes in heart rate and oxygen saturation in neonates (57). Other studies have shown that the aroma of breastmilk and lavender can prevent increasing pulse rate and reduce oxygen saturation and pain score measured using NIPS (58). However, other studies suggest that the use of aromatherapy does not significantly affect pain (59). Despite the promising results presented here, research on the use of aromatherapy in procedural pain management in neonates remains limited and involves limited samples. Further standardized clinical trials

\section{REFERENCES}

1. Cruz MD, Fernandes AM, Oliveira CR. Epidemiology of painful procedures performed in neonates: a systematic review of observational studies. Eur J Pain. (2016) 20:489-98. doi: 10.1002/ejp.757

2. Orovec A, Disher T, Caddell K, Campbell-Yeo M. Assessment and management of procedural pain during the entire neonatal intensive care unit hospitalization. Pain Manag Nurs. (2019) 20:503-11. doi: 10.1016/j.pmn.2018.11.061

3. Courtois E, Cimerman P, Dubuche V, Goiset M-F, Orfèvre C, Lagarde A, et al. The burden of venipuncture pain in neonatal intensive care units: EPIPPAIN 2, a prospective observational study. Int J Nurs Stud. (2016) 57:48-59. doi: 10.1016/j.ijnurstu.2016.01.014

4. Stevens B, Yamada J, Ohlsson A, Haliburton S, Shorkey A. Sucrose for analgesia in newborn infants undergoing painful procedures (Review). Cochrane Database Syst Rev. (2016) 7:CD001069. doi: 10.1002/14651858.CD001069.pub5

5. Vinall J, Grunau RE. Impact of repeated procedural painrelated stress in infants born very preterm. Pediatr Res. (2014) 75:584-7. doi: 10.1038/pr.2014.16

6. Mangat AK, Oei J-L, Chen K, Quah-Smith I, Schmölzer G. A review of non-pharmacological treatments for pain management in newborn infants. Children. (2018) 5:130. doi: 10.3390/children5100130

7. Bellieni CV, Tei M, Buonocore G. Contextualized pain management in newborns. J Pediatr Neonatal Individ Med. (2016) 5:1-7. doi: 10.7363/050209

8. Hall RW, Anand KJS. Pain management in newborns. Clin perinatol. (2014) 42:895-924. doi: 10.1016/j.clp.2014.08.010 must be conducted as well as standardizing the intervention protocols for administering aromatherapies to neonates.

\section{CONCLUSION}

This mini review demonstrates the potential benefits of cultural practices in managing procedural pain in neonates despite the studies presented having limitations in their trial designs, standardization of procedures, and outcome measures. The benefits of cultural practices in pain management in neonates exist not only through the effect that can be objectively measured but also through the processes and beliefs that underlie these practices. A balanced research approach is needed to reveal the objective pain relief benefits of culturally based methods of procedural pain management in neonates and the effect of the subjective meaning of cultural approaches in such pain management.

\section{AUTHOR CONTRIBUTIONS}

SF: conceived and planned the review. VW: designed the study, interpreting the results and worked on the manuscript. WR: wrote the manuscript with input from all authors. TP: contributed to the interpretation of the results. SH: worked out almost all of the technical details. All authors contributed to the article and approved the submitted version.

\section{FUNDING}

This study was funded by the Universitas Padjadjaran, Indonesia (no. 1733/UN6.3.1/LT/2020).
9. Walter-Nicolet E, Annequin D, Biran V, Mitanchez D, Tourniaire B. Pain management in newborns: from prevention to treatment. Pediatr Drugs. (2010) 12:353-65. doi: 10.2165/11318900-000000000-00000

10. Campbell-Yeo M, Fernandes A, Johnston C. Procedural pain management for neonates using nonpharmacological strategies. Adv Neonatal Care. (2011) 11:312-8. doi: 10.1097/ANC.0b013e318229aa76

11. Witt N, Coynor S, Edwards C, Bradshaw H. A guide to pain assessment and management in the neonate. Curr Emerg Hosp Med Rep. (2016) 4:110. doi: 10.1007/s40138-016-0089-y

12. Bangari A, Thapliyal SK, Ruchi R, Aggarwal B, Sharma U. Traditional beliefs and practices in newborn care among mothers in a tertiary care centre in Dehradun, Uttarakhand, India. Int J Community Med Public Health. (2019) 6:2600. doi: 10.18203/2394-6040.ijcmph20192330

13. Leininger MM. Transcultural nursing as a global care humanizer, diversifier, and unifier. Hoitotiede. (1997) 9:219-25.

14. Narayan MC. Culture's effects on pain assessment and management. Am J Nurs. (2010) 110:38-47. doi: 10.1097/01.NAJ.0000370157.33223.6d

15. Sujatha R. Cultural practices and beliefs on newborn care among mothers in a selected hospital of mangalore taluk. Nitte Univ J Heal Sci. (2014) 4:2249-7110.

16. Kawakita K, Okada K. Acupuncture therapy: mechanism of action, efficacy, and safety: a potential intervention for psychogenic disorders? Biopsychosoc Med. (2014) 8:1-7. doi: 10.1186/1751-0759-8-4

17. Lin JG, Chen WL. Acupuncture analgesia: a review of its mechanisms of actions. Am J Chin Med. (2008) 36:635-45. doi: 10.1142/S0192415X08006107

18. Michael T, Stockert K. Acupuncture in neonates-old experience or new evidence? J Neonatal Biol. (2013) 2:1-5. doi: 10.4172/2167-0897.1000114 
19. Raith W, Urlesberger B, Schmölzer GM. Efficacy and safety of acupuncture in preterm and term infants. Evid Based Comp Altern Med. (2013) 2013:739414. doi: 10.1155/2013/739414

20. Chen KL, Quah-Smith I, Schmölzer GM, Niemtzow R, Oei JL. Acupuncture in the neonatal intensive care unit - using ancient medicine to help today's babies: a review. J Perinatol. (2017) 37:749-56. doi: 10.1038/jp.20 16.227

21. Ecevit A, Ince DA, Tarcan A, Cabioglu MT, Kurt A. Acupuncture in preterm babies during minor painful procedures. J Tradit Chinese Med. (2011) 31:30810. doi: 10.1016/S0254-6272(12)60009-0

22. Abbasoglu A, Cabioglu MT, Tugcu AU, Ince DA, Tekindal MA, Ecevit A, et al. Acupressure at BL60 and K3 points before heel lancing in preterm infants. Explor J Sci Heal. (2015) 11:363-6. doi: 10.1016/j.explore.2015.07.005

23. Abbasoglu A, Cabioglu MT, Tugcu AU, Yapakci E, Tekindal MA, Tarcan A. Laser acupuncture before heel lancing for pain management in healthy term newborns: a randomised controlled trial. Acupunct Med. (2015) 33:44550. doi: 10.1136/acupmed-2015-010765

24. Mitchell AJ, Hall RW, Golianu B, Yates CC, Williams DK, Chang J, et al. Does noninvasive electrical stimulation of acupuncture Points (NESAP) reduce heelstick pain in neonates? Acta Pediatr. (2016) 105:14349. doi: 10.1111/apa.13581

25. Yates CC, Mitchell AJ, Lowe LM, Lee A, Hall RW. Safety of noninvasive electrical stimulation of acupuncture points during a routine neonatal heel stick. Med Acupunct. (2013) 25:285-90. doi: 10.1089/acu.2012.0952

26. Koç Özkan T, Simşek Küçükkelepçe D, Aydin Özkan S. The effects of acupressure and foot massage on pain during heel lancing in neonates: a randomized controlled trial. Comp Ther Med. (2019) 46:1038. doi: 10.1016/j.ctim.2019.08.004

27. la Tugcu AU, Cabioglu T, Abbasoglu A, Ecevit A, Ince DA, Tarcan A. Evaluation of peripheral perfusion in term newborns before and after Yintang (EX-HN 3) massage. J Tradit Chin Med. (2015) 35:6425. doi: 10.1016/S0254-6272(15)30153-9

28. Chen KL, Lindrea KB, Quah-Smith I, Schmolzer GM, Daly M, Schindler T, et al. Magnetic noninvasive acupuncture for infant comfort (MAGNIFIC)a single -blinded randomised controlled pilot trial. Acta Pediatr. (2017) 106:1780-6. doi: 10.1111/apa.14002

29. Vickers A, Zollman C. ABC of complementary medicine: acupuncture. $\mathrm{Br}$ Med J. (1999) 319:973. doi: 10.1136/bmj.319.7215.973

30. Raith W. Auricular medicine in neonatal care. Med Acupunct. (2018) 30:13840. doi: 10.1089/acu.2018.1299

31. Aymar CLG de, Lima LS de, Santos CMR dos, Moreno EAC, Coutinho SB. Pain assessment and management in the NICU: analysis of an educational intervention for health professionals. J Pediatr. (2014) 90:30815. doi: 10.1016/j.jpedp.2013.09.008

32. Quah-Smith I. Auriculotherapy: alleviating pain and distress in neonates in the intensive care unit. Med Acupunct. (2015) 27:409-10. doi: 10.1089/acu.2015.1119

33. Zhang K, Chen B, Zhong-Zheng L, Ding S, Lu Z, Yu H, et al. Overview of the acupuncture parts in the cochrane database of systematic reviews and the Cochrane Collaboration. World J Acupunct Moxibustion. (2016) 26:50-60. doi: 10.1016/S1003-5257(17)30024-7

34. Stadler J, Raith W, Milder LP, Schmolzer GM, Urlesberger B. Invasive and non-invasive acupuncture techniques for pain management in neonates: a systematic review. Acupunct Med. (2019) 37:201-10. doi: 10.1136/acupmed-2017-011549

35. Mitzel-Wilkinson A. Massage therapy as a nursing practice. Holist Nurs Pract. (2000) 14:48-56. doi: 10.1097/00004650-200001000-00009

36. Kong LJ, Zhan HS, Cheng YW, Yuan WA, Chen B, Fang M. Massage therapy for neck and shoulder pain: a systematic review and meta-analysis. Evid Based Comp Altern Med. (2013) 2013:613279 doi: 10.1155/2013/6 13279

37. Kulkarni A, Kaushik JS, Gupta P, Sharma H, Agrawal R. Massage and touch therapy in neonates: the current evidence. Indian Pediatr. (2010) 47:7716. doi: 10.1007/s13312-010-0114-2

38. Wang HL, Keck JF. Foot and hand massage as an intervention for postoperative pain. Pain Manag Nurs. (2004) 5:5965. doi: 10.1016/j.pmn.2004.01.002

39. Ibrahim EM, El-giundy SR, Rashad HM, Mebed MH. Effect of foot massage on pain responses to heel stick in preterm infants. Med J Cairo Univ. (2016) 84:25-31.
40. Samadi N, Allahyari I, Mazaheri E, Rostamnejad M, Namadi M, Naseri R, et al. Effect of foot reflexology on physiologic index of neonates. Iran J Neonatol. (2014) 5:19-22.

41. Fan KW. Foot massage in chinese medical history. J Altern Complement Med. (2006) 12:1-3. doi: 10.1089/acm.2006.12.1

42. Denise T. Reflexology in Pregnancy and Childbirth. London: Elsevier Ltd (2010).p. 176

43. Karatas N, Dalgic AI. Effects of reflexology on child health: a systematic review. Comp Ther Med. (2020) 50:102364. doi: 10.1016/j.ctim.2020.102364

44. Koc T, Gozen D. The effect of foot reflexology on acute pain in infants: a randomized controlled trial. Worldviews Evid Based Nurs. (2015) 12:28996. doi: 10.1111/wvn.12099

45. Gao H, Li M, Gao H, Xu G, Li F, Zhou J, et al. Effect of non-nutritive sucking and sucrose alone and in combination for repeated procedural pain in preterm infants: a randomized controlled trial. Int J Nurs Stud. (2018) 83:25-33. doi: 10.1016/j.ijnurstu.2018.04.006

46. Im H, Kim E, Park E, Sung K, Oh W. Pain reduction of heel stick in neonates: Yakson compared to non-nutritive sucking. J Trop Pediatr. (2008) 54:31-5. doi: 10.1093/tropej/fmm083

47. Im H, Kim E, Cain KC. Acute effects of Yakson and gentle human touch on the behavioral state of preterm infants. J Child Heal Care. (2009) 13:21226. doi: $10.1177 / 1367493509337441$

48. Eshghi F, Iranmanesh S, Bahman Bijari B, Borhani F, Motamed Jahromi M. Effects of Yakson therapeutic touch on the behavioral response of premature infants. J Babol Univ Med Sci. (2015) 17:15-21.

49. Bahman Bijari B, Iranmanesh S, Eshghi F, Baneshi MR. Gentle human touch and Yakson: the effect on preterm's behavioral reactions. ISRN Nurs. (2012) 2012:1-6. doi: 10.5402/2012/750363

50. Parashar P, Samuel AJ, Bansal A, Aranka VP. Yakson touch as a part of early intervention in the neonatal intensive care unit: a systematic narrative review. Indian J Crit Care Med. (2016) 20:349-52. doi: 10.4103/0972-5229.183897

51. Kim J. A concept analysis on the use of Yakson in the NICU. J Obstet Gynecol Neonatal Nurs. (2016) 45:836-41. doi: 10.1016/j.jogn.2016.07.009

52. Adam K, Oswald I. Sleep helps healing. Br Med J. (1984) 289:14001. doi: $10.1136 / \mathrm{bmj} .289 .6456 .1400$

53. Goldstein T, Moore BM, Peters RJ, Poulton C, Watson S, August W. The Aromatherapy Handbook. (2006). Available online at: http://www. recipes4success.net/support-files/aromatherapyhandbook.pdf

54. Badiee Z, Asghari M, Mohammadizadeh M. The calming effect of maternal breast milk odor on premature infants. Pediatr Neonatol. (2013) 54:3225. doi: 10.1016/j.pedneo.2013.04.004

55. Simonse AE, Mulder PGH. Analgesic effect of breast milk versus sucrose for analgesia during heel lance in late preterm infants. Pediatrics. (2012) 129:657-63. doi: 10.1542/peds.2011-2173

56. Jebreili M, Neshat H, Seyyedrasouli A, Ghojazade M, Hosseini MB, Hamishehkar H. Comparison of breastmilk odor and vanilla odor on mitigating premature infants' response to pain during and after venipuncture. Breastfeed Med. (2015) 10:362-5. doi: 10.1089/bfm.2015.0060

57. Neshat H, Jebreili $M$, Seyyedrasouli A. Effects of breast milk and vanilla odors on premature neonate' $s$ heart rate and blood oxygen saturation during and after venipuncture. Pediatr Neonatol. (2016) 57:22531. doi: 10.1016/j.pedneo.2015.09.004

58. Akcan E, Polat S. Comparative effect of the smells of amniotic fluid, breast milk, and lavender on newborns' pain during heel lance. Breastfeed Med. (2016) 11:309-14. doi: 10.1089/bfm.2015.0174

59. Bellieni C V, Cordelli DM, Marchi S, Ceccarelli S, Perrone S, Maffei M, et al. Sensorial saturation for neonatal analgesia. Clin J Pain. (2007) 23:21921. doi: 10.1097/AJP.0b013e31802e3bd7

Conflict of Interest: The authors declare that the research was conducted in the absence of any commercial or financial relationships that could be construed as a potential conflict of interest.

Copyright (๑ 2020 Fitri, Wardhani, Rakhmawati, Pahria and Hendrawati. This is an open-access article distributed under the terms of the Creative Commons Attribution License (CC BY). The use, distribution or reproduction in other forums is permitted, provided the original author(s) and the copyright owner $(s)$ are credited and that the original publication in this journal is cited, in accordance with accepted academic practice. No use, distribution or reproduction is permitted which does not comply with these terms. 